\title{
Development of a mutual-assistance capability training program to safeguard the health of local residents in evacuation shelters after a disaster
}

\author{
Michiko Takeda ${ }^{1,2)}$ and Toshiko Tada ${ }^{3)}$ \\ ${ }^{11}$ Major in Health Sciences, Graduate School of Health Sciences, the University of Tokushima, Tokushima, \\ Japan, ${ }^{2}$ Department of Nursing, Shikoku University, Tokushima, Japan, ${ }^{3}$ Department of Community \\ Nursing, Major in Nursing, Institute of Health Biosciences, the University of Tokushima Graduate \\ School, Tokushima, Japan
}

\begin{abstract}
The purpose of this study is to create and evaluate a program to enhance the mutual-assistance capability of community members to safeguard their health during time spent in evacuation shelters after a disaster. In previous research, "Supporting people in need of assistance after a disaster," the participants' awareness of the need for mutual assistance was low and their relevant knowledge and skills were insufficient. Accordingly, this became a priority in the developed program. Twenty-eight people at six different facilities participated in the program. We collected data using a questionnaire survey and group interview with the participants. After conducting the program, the participants' mean scores of mutual-assistance capability were higher than the mean pre-study scores for 25 out of 26 items. The results of group interview implied that the participants acquired [Realization of issues], and not only shared a [Sense of crisis among participants] but also felt a [Sense of responsibility for mutual assistance in the community]. We considered that our mutual-assistance training program at the time of a disaster is effective for developing mutual assistance for safeguarding health where local residents are unprepared to support those in evacuation shelters requiring assistance after a disaster. J. Med. Invest. 61 : 94-102, February, 2014
\end{abstract}

Keywords : disaster, mutual-assistance capability, program, local residents

\section{INTRODUCTION}

The number of natural disasters has been increasing worldwide over the last 30 years, and so has the number of disaster victims (1). As natural disasters are inevitable, proactive approaches to reduce potential damage are a key issue in protecting our

Received for publication December 2, 2013 ; accepted December 17, 2013.

Address correspondence and reprint requests to Michiko Takeda, Department of Nursing, Shikoku University, 123-1 Ebisuno, Furukawa Oujin-cho, Tokushima 771-1192, Japan and Fax : +8188-665-8037. everyday lives. The waning of community mutual assistance, insufficient passing down of disaster experiences and the vulnerability to disasters due to changes in lifestyle contribute to the increase in disaster-related damage (2).

Since the Kobe earthquake in 1995, the significance of mutual assistance for evacuation and rescue has garnered increasing attention (3). Dramatic changes and long-term stress in people's lives in evacuation shelters may cause a sharp increase in the occurrence of infectious diseases and exacerbate chronic diseases (4). Nevertheless, little attention has been paid to mutual assistance among local 
residents for health maintenance while they are in an evacuation shelter. It has been reported that social connection and mutual support (5) within a community are important (6) for reducing disaster-related damage. Further, there is not only a need for adequate balance among self-help, mutual assistance and public help, but also a need to improve mutual assistance by promoting group activities in the community (7).

A disaster-prepared community has planned activities and events, for instance festivals, to promote mutual assistance that have become well-established (8). It has been reported that a passion for the community needs to be developed in daily-life (9). Thus, we consider a disaster-preparedness training program as an effective means of regional disasterprevention education, in order to improve the mutual assistance for safeguarding public health.

However, current disaster-prevention training programs only include education programs on first-aid procedures for community residents, disaster drills in cooperation with universities and the community (10), disaster imagination games (11), promotion of self-help (12) and programs for pregnant women (13). To the best of our knowledge, there are currently no programs that aim to improve the mutual assistance for safeguarding the health of those staying in evacuation shelters.

Consequently, we conducted a group interview with local leaders (community associations' leaders, presidents of regional senior citizens' clubs/associations and leaders of volunteer organizations) who spent time in an evacuation shelter after the Niigata Prefecture Chuetsu Earthquake in 2004. The interview was conducted to clarify what approaches the local residents took toward mutual assistance for safeguarding their health. As a result, the following categories were extracted in relation to mutual assistance for safeguarding health of those in evacuation shelters : "Mutual assistance to prevent physical and mental disorders," "Supporting people in need of assistance at the time of a disaster," and "Establishing neighborly relations" (14). Based on codes allocated to these categories, we prepared a questionnaire and conducted a questionnaire survey targeting local disaster-response leaders from Prefecture A who had no disaster experience. This survey was to clarify what was required in the mutualassistance training for safeguarding health. The results revealed that the local disaster-response leaders were ill-aware of and ill-prepared for the need for mutual assistance to support those requiring assistance at the time of a disaster (15).

Thus, the purpose of this study is to create and evaluate a program to enhance the mutual-assistance capability of community members to safeguard their health during time spent in evacuation shelters after a disaster.

In the present study, the mutual-assistance capability for safeguarding health (hereinafter, "MAC") was defined as mutual help among local residents to prevent their health from worsening while they are staying in an evacuation shelter, where public healthcare and social welfare resources are limited.

\section{PARTICIPANTS AND METHODS}

\section{Development of the MAC Training Program (hereinafter, "the program")}

\section{(1) Extraction of the program details}

In relation to "Supporting people in need of assistance at the time of a disaster (people in need of assistance)," the participants' awareness of the need for MAC was low and their relevant knowledge and skills were insufficient (15). Accordingly, this became a priority in the program.

(2) Planning and implementation of the program

We created the program by employing the Disaster Prevention Game Method (16), which is a means for risk communication. The Disaster Prevention Game is a method in which the participants do not merely receive risk information from experts in a unilateral manner but also experience simulated disasters and learn how to participate in decisionmaking through the reciprocal process of exchanging risk information and opinions among individuals, organizations and groups (17).

\section{(3) Establishing purposes of the program}

With regard to the MAC of disaster-response leaders, the following items were lacking : "Support required for infants at the time of a disaster" and "Knowing the methods for evacuating the visually or hearing impaired" (15). Based on these deficiencies, the program aimed to develop the MAC for support of people in need of assistance at the time of a disaster.

\section{Participants and Recruiting Methods}

The participants were those residents who had a high level of interest in disaster prevention, who were in Prefecture A where there had not been earthquakes above seismic scale 5 according to the Japanese Meteorological Agency lintensity in recent 
years, and who consented to participate in the program. We checked whether participants in a previous study (15) were willing to participate in the present study. Consequently, 28 people from the previous study agreed to participate in the present study.

\section{Time and Methods for Creating and Implement- ing the Program}

(1) Time for creating the program

The program was created between July and September 2012.

(2) Pretesting

Two groups consisting of six to seven participants pretested the trial program and the participants made modifications to the program.

(3) Preparation for implementing the program

The program operator had over 20 years of experience as a public health nurse and experience in planning and managing workshops for local residents and in participating in disaster prevention workshops.

(4) Educational materials and implementation of the program

Between December 2012 and March 2013, the program was implemented in urban and mountainous areas in A prefecture. The venues used were six public facilities such as community halls. Desks were arranged so that the participants were able to see each other's face. We used projectors to display our own PowerPoint slides, and distributed hardcopies of the slides.

We asked two questions for the disaster prevention game : "Whether to ask disaster victims for help in guiding the visually or hearing impaired when care volunteers are busy" and "Whether to talk with mothers when their breast-fed infants start crying." After receiving an explanation about the process of developing the program and the procedures in the disaster prevention game, the participants exchanged their opinions regarding the above questions based on example cases.

\section{Data Collection and Analytical Methods}

\section{1) Questionnaire survey}

\section{(1) Data collection method}

The research items in our previous study consisted of 26 items on the need for the MAC and 26 items on the preparedness for the MAC (15).

The questionnaire was distributed at the venues between December 2012 and March 2013, and collected on the spot.

\section{(2) Analytical methods}

The participants' awareness of and preparedness for the need for mutual assistance before and after the program were aggregated (the Wilcoxon signed rank-sum test). $P$ values $<0.05$ were considered as significant differences.

2) Group interview

\section{(1) Data collection methods}

We conducted a group interview with the program participants upon completion of the program. The details of the interview included whether it was possible to implement the program in their regions, and whether the implementation would enhance MAC of the local residents in their areas.

\section{(2) Analytical methods}

We recorded the interview results and employed content analysis methods for codification and categorization of the interview contents.

\section{Ethical Consideration}

Approval for this research was obtained from the Ethics Review Board of the university to which the authors belong (Approval No. 1321).

\section{RESULTS}

\section{Characteristics of participants}

The participants were 28 men with a mean age of $67.1 \pm$ (SD) 5.9 years. The number of participants at each of the venues ranged from two to seven.

\section{Questionnaire survey}

1) Changes in the awareness of and preparedness for the need for MAC immediately after participating in the program.

\section{(1) Preparedness for MAC (Table 1)}

The mean score for the participants' preparedness for MAC was high for 25 out of 26 items after participation in the program. Among the 25 items, the mean scores for the following three items were significantly high : "I can considerately listen to disaster victims" ( $p=0.018)$, "I can prepare for hot or cold weather without using electricity" $(p=0.023)$ and "I can devise facilities such as the toilet" ( $p=$ 0.049). Further, the scores in "I can check a person's health condition from the color of his/her face" $(p=0.077)$ tended to be high. In relation to changes in the minimum scores, the minimum scores in five out of 26 items changed from one to three, and the minimum scores in nine items changed from one to two. 
Table 1. Changes in Program Participants' Preparedness for Mutual Assistance

\begin{tabular}{|c|c|c|c|c|c|c|}
\hline Items & Time & $\begin{array}{l}\text { average } \\
\text { value }\end{array}$ & $\mathrm{SD}$ & $\begin{array}{l}\text { Min. } \\
\text { value }\end{array}$ & $\begin{array}{l}\text { Max. } \\
\text { value }\end{array}$ & $\begin{array}{l}\text { Significance } \\
\text { probability } \\
\text { (two-sided) }\end{array}$ \\
\hline \multirow{2}{*}{ Considerately listening to disaster victims } & Before & 3.7 & 0.8 & 2 & 5 & \multirow{2}{*}{.018} \\
\hline & After & 4.1 & 0.6 & 3 & 5 & \\
\hline \multirow{2}{*}{ Preparing for hot/cold weather without using electricity } & Before & 3.4 & 1.0 & 1 & 5 & \multirow{2}{*}{.023} \\
\hline & After & 3.8 & 0.8 & 2 & 5 & \\
\hline \multirow{2}{*}{ Devising facilities such as the toilet } & Before & 3.5 & 1.0 & 1 & 5 & \multirow{2}{*}{.049} \\
\hline & After & 3.8 & 0.8 & 3 & 5 & \\
\hline \multirow{2}{*}{$\begin{array}{l}\text { Checking a person's health condition from the color } \\
\text { of his/her face, etc. }\end{array}$} & Before & 3.2 & 1.1 & 1 & 5 & \multirow{2}{*}{.077} \\
\hline & After & 3.5 & 1.0 & 1 & 5 & \\
\hline \multirow{2}{*}{$\begin{array}{l}\text { Collecting information for receiving daily-life support } \\
\text { services }\end{array}$} & Before & 3.7 & 1.0 & 1 & 5 & \multirow{2}{*}{.109} \\
\hline & After & 3.9 & 0.8 & 2 & 5 & \\
\hline \multirow{2}{*}{$\begin{array}{l}\text { Rescuing and giving aid to each other among local } \\
\text { residents }\end{array}$} & Before & 3.8 & 0.8 & 2 & 5 & \multirow{2}{*}{.109} \\
\hline & After & 4.0 & 0.7 & 2 & 5 & \\
\hline \multirow{2}{*}{$\begin{array}{l}\text { Methods for preventing pulmonary thrombosis caused } \\
\text { by being in the same posture for a long time }\end{array}$} & Before & 3.3 & 1.3 & 1 & 5 & \multirow{2}{*}{.161} \\
\hline & After & 3.7 & 1.0 & 2 & 5 & \\
\hline \multirow{2}{*}{$\begin{array}{l}\text { Methods for preventing the loss of body strength due } \\
\text { to the lack of activity }\end{array}$} & Before & 3.6 & 1.0 & 1 & 5 & \multirow{2}{*}{.825} \\
\hline & After & 3.6 & 0.9 & 2 & 5 & \\
\hline \multirow{2}{*}{ Methods for preventing group infection such as influenza } & Before & 3.7 & 0.9 & 1 & 5 & \multirow{2}{*}{.847} \\
\hline & After & 3.6 & 0.9 & 2 & 5 & \\
\hline \multirow{2}{*}{ Judging whether medical consultation is required or not } & Before & 3.0 & 1.3 & 1 & 5 & 433 \\
\hline & After & 3.3 & 1.1 & 1 & 5 & .435 \\
\hline Devisino wavs to maintain dietary life & Before & 3.3 & 1.2 & 1 & 5 & 457 \\
\hline Devising ways to maintain dietary life & After & 3.4 & 0.9 & 2 & 5 & .456 \\
\hline Noticino neonle who have been mentally hurt by dicaster & Before & 3.4 & 1.1 & 1 & 5 & 490 \\
\hline Noucing peopre who mave Deen mentany hurt dy usaster & After & 3.5 & 0.9 & 1 & 5 & .490 \\
\hline Paying attention to each other among disaster victims & Before & 4.0 & 0.9 & 2 & 5 & \\
\hline by talking to them & After & 4.1 & 0.6 & 3 & 5 & .260 \\
\hline Knowing the names and addresses of people in need & Before & 3.5 & 1.3 & 1 & 5 & 260 \\
\hline of assistance in the community & After & 3.8 & 1.2 & 2 & 5 & .260 \\
\hline Methods for evacuating people with visual and hearing & Before & 3.0 & 1.2 & 1 & 5 & 624 \\
\hline disabilities & After & 3.1 & 1.0 & 1 & 5 & .624 \\
\hline Knowing how to take care of the elderly & Before & 3.1 & 1.2 & 1 & 5 & 274 \\
\hline Knowing now to take care or the elderly & After & 3.3 & 0.9 & 2 & 5 & .274 \\
\hline Sunnort required for the elderly at the time of disaster & Before & 3.1 & 1.1 & 1 & 5 & 163 \\
\hline support required for the elderly at the time of disaster & After & 3.4 & 1.1 & 1 & 5 & .163 \\
\hline Sunnort recuired for infants at the time of disaster & Before & 2.9 & 1.3 & 1 & 5 & 154 \\
\hline Support required ior iniants at the time of disaster & After & 3.3 & 1.1 & 1 & 5 & .154 \\
\hline Knowino which nublic authorities to contact & Before & 4.3 & 1.0 & 1 & 5 & 289 \\
\hline Knowing which public authorities to contact & After & 4.5 & 0.6 & 3 & 5 & .289 \\
\hline Methods for manaoino an evacuation shelter & Before & 3.6 & 1.2 & 1 & 5 & 289 \\
\hline Methods for managing an evacuation snelter & After & 3.9 & 1.0 & 2 & 5 & .289 \\
\hline Communicating appropriate information to public & Before & 4.1 & 1.0 & 2 & 5 & 653 \\
\hline authorities & After & 4.2 & 0.7 & 3 & 5 & .005 \\
\hline Cooneratino with each other in an evacuation shelter & Before & 4.1 & 0.7 & 3 & 5 & 317 \\
\hline Cooperating with eacn other in an evacuation snelter & After & 4.3 & 0.6 & 3 & 5 & .316 \\
\hline Deciding rules for the life in an evacuation shelter & Before & 4.1 & 0.8 & 2 & 5 & 134 \\
\hline through discussion & After & 4.3 & 0.6 & 3 & 5 & .134 \\
\hline Solving new issues in an evacuation shelter through & Before & 4.0 & 0.9 & 1 & 5 & 251 \\
\hline discussion & After & 4.2 & 0.7 & 3 & 5 & .201 \\
\hline Recuestino local residents to share roles & Before & 4.1 & 0.9 & 1 & 5 & 225 \\
\hline Kequesting local restuents to snare roies & After & 4.3 & 0.6 & 3 & 5 & .225 \\
\hline Clarifying the system for the leader's command and & Before & 4.1 & 0.9 & 1 & 5 & \\
\hline control & After & 4.3 & 0.6 & 3 & 5 & .040 \\
\hline
\end{tabular}

- Wilcoxon signed-rank sum test

- Five-stage Evaluation is used : 5 scores for "Know well" to 1 score for "Do not know at all" ; or 5 scores for "Can do it well" to 1 score for "Cannot do it at all" 


\section{(2) Awareness of the need for MAC}

The comparison of the scores before and after participation in the program revealed that there was an increase in 16 out of 26 items after participation. On the other hand, there was a decline in nine items, and the score of one item remained the same. The changes were not significant for any of the items.

\section{Group interview}

As a result of the analysis of the participants' responses about the significance of the program, 19 codes, five subcategories and three categories were extracted (Table 2).

The results implied that the participants acquired [Realization of issues], and not only shared a [Sense of crisis among participants] but also felt a [Sense of responsibility for mutual assistance in the community]. Herein, the categories are marked with [ ], the subcategories with \langle\rangle , and the representative codes with " ". Regarding the descriptions of the codes, the representative responses were summarized while preserving their meanings.

1) [Realization of issues]

This category means that the participants realized the issues associated with mutual assistance by exchanging opinions among themselves. Even though the participants did not have specific knowledge of disaster prevention, they had opportunities to speak, stating, "Everyone can participate in opinion exchange." From this, they understood that "There can be unexpected opinions." Based on the opinions, participants found it "Possible to actively learn through thinking and speaking out on my own," so that they were not mere recipients but able to $\langle$ Realize issues with mutual assistance from various aspects $\rangle$. Given these responses, we named the category [Realization of issues].

\section{2) [Sense of crisis among the participants]}

This category means that the participants shared a [Sense of crisis among the participants] through 〈Feeling the mutual assistance of the other participants' areas as your area's mutual assistance $\rangle$ and

Table 2. Results of Post-Program Interview with Participants

\begin{tabular}{|c|c|c|}
\hline Categories (3) & Subcategories (5) & Codes (19) \\
\hline \multirow{3}{*}{ Realization of issues } & \multirow{3}{*}{$\begin{array}{l}\text { Realizing issues with } \\
\text { mutual-assistance from } \\
\text { various aspects }\end{array}$} & Everyone can participate in opinion exchange \\
\hline & & There can be unexpected opinions \\
\hline & & $\begin{array}{l}\text { Possible to actively learn through thinking and speaking out on my } \\
\text { own }\end{array}$ \\
\hline \multirow{8}{*}{$\begin{array}{l}\text { Sense of crisis among } \\
\text { the participants }\end{array}$} & \multirow{5}{*}{$\begin{array}{l}\text { Ability to image critical problems } \\
\text { in mutual-assistance }\end{array}$} & $\begin{array}{l}\text { Opportunity to know potential problems in the life in an evacuation } \\
\text { shelter }\end{array}$ \\
\hline & & $\begin{array}{l}\text { No choice but to support people in need of assistance although I } \\
\text { have felt difficult to deal with them }\end{array}$ \\
\hline & & The program leads to enhancement of crisis awareness \\
\hline & & $\begin{array}{l}\text { Understanding that the situation continuously changes during a } \\
\text { disaster }\end{array}$ \\
\hline & & $\begin{array}{l}\text { Understanding that decisions must be made quickly regarding the } \\
\text { situation arisen. }\end{array}$ \\
\hline & \multirow{3}{*}{$\begin{array}{l}\text { Feeling the mutual-assistance of } \\
\text { the other participants' areas as } \\
\text { your area's mutual-assistance }\end{array}$} & Reflecting on my resident area in spite of myself \\
\hline & & Imaged potential problems that would arise in my own area \\
\hline & & $\begin{array}{l}\text { Worried about the problems and preparedness of my own resident } \\
\text { area as I answer the questions }\end{array}$ \\
\hline \multirow{8}{*}{$\begin{array}{l}\text { Sense of responsibility } \\
\text { for mutual-assistance } \\
\text { in the community }\end{array}$} & \multirow{5}{*}{$\begin{array}{l}\text { Motivation for developing an } \\
\text { implementation structure for } \\
\text { the program }\end{array}$} & $\begin{array}{l}\text { The operation of the program is complex and requires a number of } \\
\text { people }\end{array}$ \\
\hline & & $\begin{array}{l}\text { Possible to implement the program in my town if public authorities } \\
\text { bear the cost }\end{array}$ \\
\hline & & Wanting others to know that there is no single right answer \\
\hline & & A brochure will be useful for communicating the basic knowledge \\
\hline & & $\begin{array}{l}\text { Desirable to have experts' explanations after the program in order } \\
\text { to deepen my understanding }\end{array}$ \\
\hline & \multirow{3}{*}{$\begin{array}{l}\text { Sense of responsibility for } \\
\text { recruiting members for working } \\
\text { on mutual-assistance together }\end{array}$} & $\begin{array}{l}\text { Wanting to communicate the need for mutual-assistance to those } \\
\text { not participating in a regional, independent disaster-prevention } \\
\text { organization }\end{array}$ \\
\hline & & $\begin{array}{l}\text { Wanting to devise ways to involve people with a low awareness of } \\
\text { mutual-assistance in the program }\end{array}$ \\
\hline & & Wanting to hear from people in need of assistance about their needs \\
\hline
\end{tabular}


acquiring the $\langle$ Ability to imagine critical problems in mutual assistance .

Their participation in the program was an "Opportunity to know potential problems associated with life in an evacuation shelter," and the participants stated that they had "No choice but to support people in need of assistance, although I have felt it difficult to deal with them," as it had been difficult for them to understand such people. The participants stated that their crisis awareness was low, as they did not have any disaster experience, but "The program leads to enhancement of crisis awareness." At the same time, the participants "Understand that the situation changes continuously during a disaster." They "Understand decisions must be made quickly regarding situations that arise." From these responses, the subcategory of $\langle$ Ability to image critical problems in mutual assistance $\rangle$ was extracted.

Furthermore, the participants associated the example cases used in the program with their own residential areas and stated that they became "Worried about the problems and preparedness of my own residential area as I answer the questions" by "Reflecting on my residential area in spite of myself" and "Imagining potential problems that would arise in my own area." From these responses, the subcategory of $\langle$ Feeling the mutual assistance of the other participants' areas as your area's mutual assistance) was extracted.

\section{3) [Sense of responsibility for mutual assistance in the community]}

This category represents the participants' awareness of the [Sense of responsibility for mutual assistance in the community] as they found the 〈Motivation for developing a structure for implementing the program $\rangle$ in their communities and felt the 〈Sense of responsibility for recruiting members for working on mutual assistance together〉.

They specifically considered ways to diffuse the program, making comments such as "The operation of the program is complex and requires a number of people" and "[It is] Possible to implement the program in my town if public authorities bear the cost." Further, some of the participants asked for a right answer even where there was no single right answer to the questions. In that situation, the other participants had the mentality of the program operator, stating that they were "Wanting others to know that there is no single right answer." They even came up with improvements such as "A brochure will be useful for communicating the basic knowledge" and "It would be desirable to have experts" explanations after the program in order to deepen my understanding." Accordingly, we named this subcategory $\langle$ Motivation for developing a system for implementing the program $\rangle$.

The participants also paid attention to those who were not willing participants in regional, independent disaster-prevention organizations as inferred from their responses such as "[I want to] communicate the need for mutual assistance to those people not participating in a regional, independent disaster-prevention organization" and "[I want to] devise ways to involve people with a low awareness of mutual assistance in the program." Additionally, they pointed out the need for bilateral consideration rather than unilateral consideration from people engaging in support, as they expressed, "[I want to] hear from people in need of assistance about their needs." Accordingly, we named this subcategory 〈Sense of responsibility for recruiting members for working on mutual assistance together〉.

\section{DISCUSSION}

This research aimed to develop and evaluate a MAC training program for safeguarding the health of local residents in evacuation shelters at the time of a disaster. The program was created to examine the details of the mutual assistance for supporting people in need of assistance, of whom local residents are ill-aware (15).

The following items regarding mutual assistance showed clear differences after the implementation of the program : "I can considerately listen to disaster victims," "I can check the health condition of a person from the color of his/her face" and "Local residents can rescue and give aid to each other." These items reflect direct mutual support for mental and physical health. Further, the following items indicate that improvements in living conditions can lead to mutual assistance of those in evacuation shelters : "I can prepare for hot or cold weather without using electricity" and "I can devise facilities such as the toilet." The details of these items on MAC relate to health maintenance and prevention of physical and mental disorders, and thus the details are applicable not only to the support for those in need of assistance but also to mutual assistance for all disaster evacuees. Improvements in MAC after participation in the program were reflected in the items, "I know the names and addresses of people in need of assistance in the community" and "I know 
how to take care of the elderly" as specific ways to support people in need of assistance. Those requiring assistance are able to avoid physical and mental diseases while living in an evacuation shelter, if they can receive the proper support when required (18). Accordingly, mutual assistance is extremely important for these individuals (19).

Although the local residents found it difficult to understand and were ill-aware of people in need of assistance (15), after the program, they became more aware of such people as the participants in their MAC. This is indicated by the enhancement of their MAC after participation in the program. For example, they stated in the group interview, "[They have] No choice but to support people in need of assistance." Presumably, through the participants' consideration among themselves on the questions asked during the program, they started to feel that they would not want to leave people in need of assistance in the case where a similar problem actually in their areas. Based on this, encouraging participants to exchange opinions when answering the questions was effective in enhancing their MAC.

The disaster prevention game, which is becoming a major method for disaster-prevention education, requires critical revision of information at the time of a crisis (20). For that reason, it is considered to be a cooperative system in which participants work toward discovering and organizing problems (16). Moreover, the disaster prevention game teaches participants three important skills : listening to others, abstract thinking and recognizing the lack of knowledge at the moment (17). One type of disaster prevention game, "Crossroad: Version for People in Need of Assistance," has been created, but is used to examine the judgment of aid workers. In the future, it will be important to share with local residents the methods for post-evacuation support of those in need of assistance. It is crucial that disaster victims not only receive support but also are able to aid others (17). Additionally, it is reported that trained local residents become a resource in an evacuation shelter (21). In developing the program, the questions were asked considering that the mutual assistance for those in need of assistance in evacuation shelters was an issue, and that the questions were to be answered from the perspective of local residents. As a result, the program led participants to realize mutual assistance for those in need of assistance, and was capable of enhancing this MAC.

The scores for the items on the development of neighborly relationships, "I can cooperate with others in an evacuation shelter" and "I know which public authorities to contact," were high even before participation in the program. This is likely because people with good neighborly relationships participated in the program. However, after participation in the program, changes in the scores suggested that the participants were able to develop a relationship in preparation for disaster. This suggests that the program fosters community resilience (22), which is important for disaster preparedness, and consequently increases the capacity of the community (23) to help in disaster recovery (24).

This result coincided with the responses from the group interview, such as "Wanting to devise ways to involve people with a low awareness of mutual assistance in the program" and "Wanting to communicate the need for mutual assistance to those not in a regional, independent disaster-prevention organization." This clearly indicates that participants changed their attitude toward a sense of responsibility for mutual assistance. Further, the response "Wanting to hear from people in need of assistance about their needs" suggests that the participants felt a sense of responsibility for increasing members with whom they would work on mutual assistance together. This coincides with the conclusion from a previous study indicating that people in need of assistance should voluntarily, rather than passively, participate in disaster-prevention activities (25).

The program enabled participants to imagine issues associated with mutual assistance. The results showed that participants realized the need for mutual assistance in their communities. Based on this, the program could be considered a form of training for the participants to exchange opinions and make decisions among themselves, and enhance their MAC to safeguard health. Unlike disaster-prevention conferences involving guest speakers, approaches such as the program developed in the present study can enable local residents, as the main actors, to continuously implement such approaches in their community. In order for local residents to work on mutual assistance as the main actors, the issues to be tackled should be those that are common among them. Moreover, local residents are required to have relationships among themselves based on day-to-day mutual support as well as a willingness to contribute to the community (26-27). In the program, the participants shared their realization regarding the given tasks and a sense of crisis, and had a sense of responsibility for mutual 
assistance in the community. Thus, local residents can be the main actors in utilization of the program.

In conclusion, we considered that the developed MAC training program was effective for developing MAC for safeguarding the health of local residents requiring assistance in evacuation shelters after a disaster. However, there is a limitation in the present study. Because sample is small size, only male and old ages, and method is multiple testing. In the future, it is necessary to increase the number of program participants and to evaluate the program over a longer period of time.

\section{CONFLICT OF INTEREST}

None of the authors has any conflicts of interest to declare.

\section{ACKNOWLEDGEMENTS}

This study was supported by JSPS KAKENHI Grant Number 22592431 (2010-2012).

We greatly appreciate all those who participated in the study.

\section{REFERENCES}

1. Science Council of Japan 2007 Report : Building a safe and secure society for the increase of natural disasters of the Earth global scale. Available at http : //www.mlit.go.jp/river/press_ blog/past_press/press/200701_06/070530/ index.html. Accessed Aug. 28, 2013.

2. Sakurai $\mathrm{S}$ : Trends and issues of disaster nursing research as seen from the overseas literature, Mie Kango Gakkaishi 13 : 1-7, 2011 (in Japanese)

3. Cabinet Office : 2010 White paper of disaster prevention. Printing Bureau. Ministry of Finance. Tokyo, 2010, pp.196-197 (in Japanese)

4. Ohara $\mathrm{M}$ : Disaster nursing to save the life and mind. Gakken, Tokyo, 2008, pp.105-108 (in Japanese)

5. Wind TR, Fordham M, Komproe IH : Social capital and post-disaster mental health. SOC SCI MED 75(9) : 1715-1720, 2012

6. Stephens $\mathrm{C}$ : Social capital in its place-Using social theory to understand social capital and inequalities in health-. SOC SCI MED 66:
1174-1184, 2008

7. Nagai A, Hishiyama K, Itakura Y, Yoshihara $\mathrm{N}$ : Sociology of disaster prevention towards the social design of disaster prevention community. Toshindou, Tokyo, 2008, pp.59-85 (in Japanese)

8. Hirata $\mathrm{K}$ : Improvement of mutual assistance powers in local communities for earthquake disaster mitigation -Present state of people's interaction and disaster drill to motivate mutual assistance for disaster mitigation in local communities in Bunkyo ward-. Japan Women's University Bulletin 58 : 101-110, 2011 (in Japanese)

9. Takahashi $\mathrm{T}$ : Messages from Kobe-ties in the local community : Japanese Journal of Disaster Medicine 11(1) : 22-28, 2006 (in Japanese)

10. Ohara $\mathrm{M}$, Hasebe $\mathrm{S}$ : The process and future plan of disaster relief education in Japanese Red Cross Musashino Junior College of Nursing -Encouragement of empowerment on the disaster prevention for student \& community with collaboration-. Japanese Red Cross Musashino Junior College of Nursing Bulletin 17 : 65-73, 2004 (in Japanese)

11. Kawahara N, Kuroda Y, Otani M, Maehara S : The implement and the effect of disaster imagination game (DIG) on the inhabitants. Journal of Japan Society of Disaster Nursing 3(3) : 3442, 2001 (in Japanese)

12. Okuno N, Mashino S, Ooshima R, Watanabe T, Uyama O, Minami H, Yamamoto A : Evaluation of community disaster education program. Journal of Japan Society of Disaster Nursing 8(2) : 41-52, 2006 (in Japanese)

13. Yasunari T, Nozawa M, Nishio R, Yamamoto A, Takami Y : Development and evaluation of 'disaster preparedness' educational program for pregnant women. Int Nurs Rev 35(2) : 31-37, 2012

14. Takeda M, Tadatsu S, Ozaki Y : Mutual health support among Chuetsu Earthquake : Journal of Japan Society of Disaster Nursing 14(3) : 214, 2013 (in Japanese)

15. Takeda $M$, Tada $T$ : Investigation on "mutualassistance capability to safeguard the health" of regional disaster-response leaders. Journal of Shikoku Public Health Society 58(1) : 192196, 2013 (in Japanese)

16. Yamori K, Kikkawa T, Ajiro T : Risk communication to learn in disaster prevention game. Nakanisiya Syuppan, Kyoto, 2012, pp.19-37 (in 
Japanese)

17. Kikkawa T, Yamori K, Sugiura J : Continue risk communication to learn the game Crossroads next. Nakanisiya Syuppan, Kyoto, 2012, pp.142191 (in Japanese)

18. Website Cabinet Office : Report of study group on the evacuation support of requiring assistance during accident. Available at http : // www.bousai.go.jp/taisaku/hisaisyagyousei/ youengosya/h24_kentoukai/. Accessed Oct. 2, 2013

19. Takahashi H, Kojima S : Guide of disaster prevention and cooperation Beyond the self-help, mutual support, public assistance. Nihon Bousai Syuppansya 2008, Tokyo, 2008, pp.107-130 (in Japanese)

20. Horiguchi I, Kikkawa T, Marui E : Risk communication training using the Crossroads - The theme of food safety-. Kousei no Sihyo 55(6) : 28-33, 2008 (in Japanese)

21. Lichterman JD : A "community as resource" strategy for disaster response. Public Health Report 115 : 262-265, 2000

22. Wells KB, Tang J, Lizaola E, Jones F, Brown A, Stayton A, Williams M, Chandra A, Eisenman D, Fogleman S, Plough A : Community resilience and public health practice -applying community engagement to disaster planning : Developing the vision and design for the Los Angeles County Community Disaster Resilience
Initiative-. Am J Public Health 103(7) : 11721180, 2013

23. Ebi KL: Resilience to the health risks of extreme weather events in a changing climate in the United States. Int J Environ Res Public Health 8(12) : 4582-4595, 2011

24. Gibbs L, Waters E, Bryants RA, Pattison P, Lusher D, Harms L, Richardson J, MacDougall C, Block K, Snowdon E, Gallagher HC, Sinnott V, Ireton G, Forbes D : Beyond bushfires: community, resilience and recovery - a longitudinal mixed method study of the medium to long term impacts of bushfires on mental health and social connectedness, BMC Public Health 13(1) : 2013. Available at http//www. biomedcentral.com/1471-2458/13/1036. Accessed Oct. 2, 2013

25. Kinoshita Y, Asano Y, Ueoka Y, Itou F : How do visiting nurses prepare for after the disaster-From interviews with people requiring assistance- Homonkango to Kaigo 15(9) : 718723, 2010 (in Japanese)

26. Takahashi K, Suenaga K, Kurimoto A, Ueno $\mathrm{T}$ : A study of health leaders-initiate in health promotion activities. Tohokudai Ihokengakka Kiyou 20(1) : 17-24, 2011 (in Japanese)

27. Motoyoshi T, Takao K, Ikeda S : Determinants of household- and community-based disaster preparedness. Japanese Society of Social Psychology 23(3) : 209-220, 2008 (in Japanese) 